\title{
CORK-Lite: Bringing Legacy Boreholes Back to Life
}

\author{
by C. Geoffrey Wheat, Katrina J. Edwards, Tom Pettigrew, Hans W. Jannasch, \\ Keir Becker, Earl E. Davis, Heiner Villinger, and Wolfgang Bach
}

\section{Introduction}

An essential aspect of the forty years of deep-sea scientific drilling has been to maximize the scientific return during each expedition while preserving samples for future investigations. This philosophy also extends to borehole design, providing the community with tens of cased legacy boreholes that penetrate into the basaltic crust, each ripe for future investigations of crustal properties and experiments to determine crustal processes (Edwards et al., 2012a). During Integrated Ocean Drilling Program (IODP) Expedition 336 to North Pond on the western flank of the Mid-Atlantic Ridge at $22^{\circ} \mathrm{N}$, Hole U1383B (Fig. 1) was planned to be a deep hole, but was abandoned when a 14.75 -inch tri-cone bit catastrophically failed at 89.9 meters below the seafloor (mbsf) (Expedition 336 Scientists, 2012). This

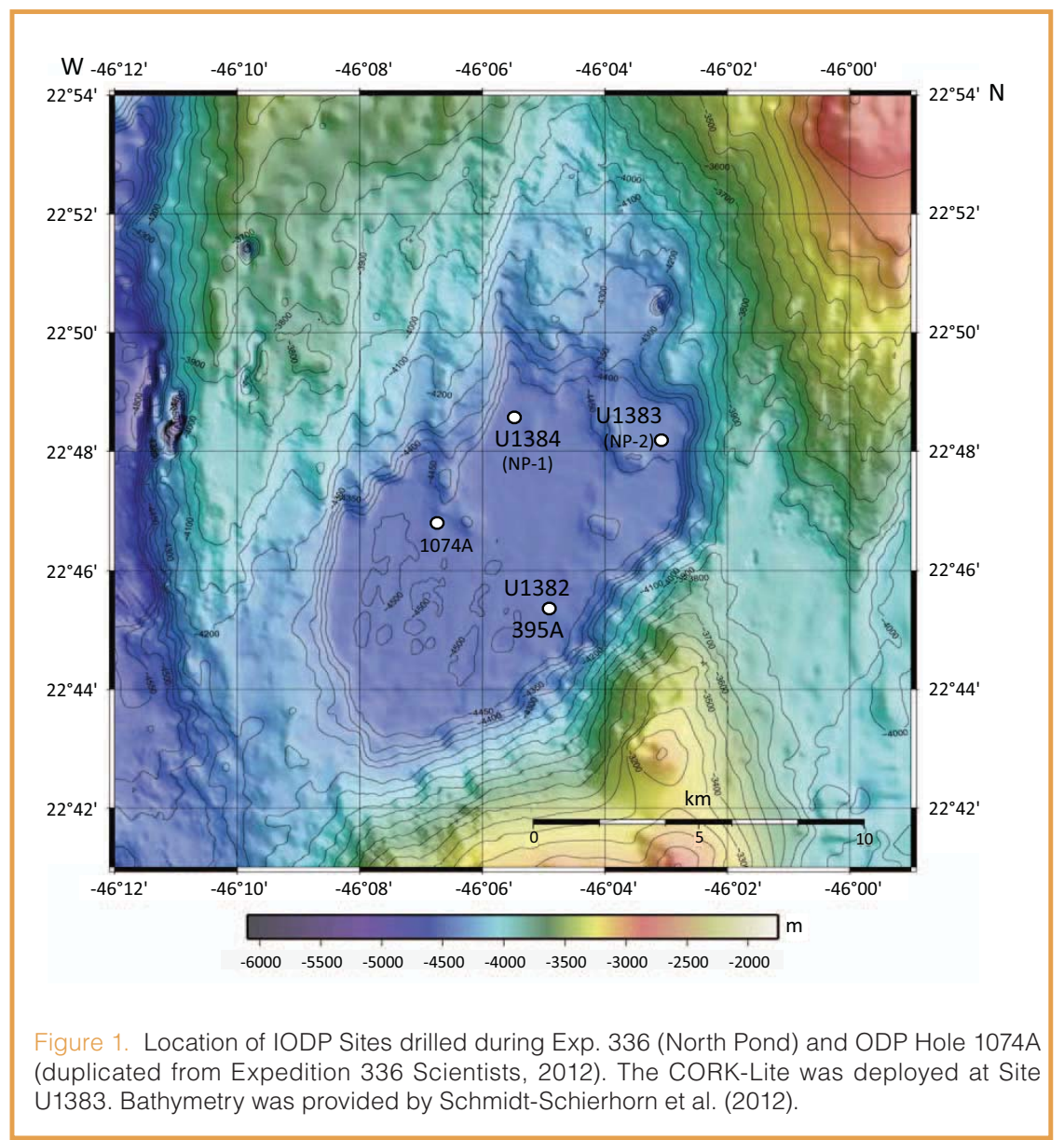

resulted in about 36 meters of open hole below casing, similar to conditions within tens of legacy boreholes. Because the overall experiment required a return to the "natural" hydrologic state in basaltic basement, it was critical to seal the hole to prevent a hydrologic "short circuit". Thus, a plan emerged at sea to seal Hole U1383B with a simplified Circulation Obviation Retrofit Kit (CORK) termed "CORK-Lite" that could be deployed by a remotely operated vehicle (ROV) on a planned dive series five months later. To prepare for this deployment, a standard ROV platform that is used with CORKs was modified to be self-guiding in the re-entry cone and deployed. The next step was to design a CORK system that could seal the borehole, yet be physically manageable with an ROV, and be ready for shipping and deployment within three months. Several key functional aspects dictated the design of the new CORK-Lite (Table 1).

\section{Design of CORK-Lite}

The CORK-Lite has four major components: the body with a seal, a removable cap, a downhole instrument string, and a borehole pressure monitoring instrument. The body is a 4.9 -m-long 12 -inch pipe with a landing seal ring that has a diameter of 19.5 inches that fits within the 32 -inch guide hole in the ROV platform (Figs. 2, 3). The landing seal ring lands on and seals in the 20-inch casing hanger. The body has hooks to hang instruments, two valve bodies that accept hydraulic connectors closed in the horizontal position (Wheat et al., 2011), two flanges (lifting wings) for deployment that also serve to aid in moving the body during ROV operations, and a grooved top ring made of stainless steel to insure a proper seal is achieved with the cap. A re-movable "boot" was designed to fit the bottom of the body to protect it during deployment and to prevent it from penetrating into the sediment during free fall. In addition, a lifting bar assembly was fabricated that connects the body to a float package and eases handling by the ROV. 
Table 1. A list of design consideration of CORK-Lite.

- The CORK-Lite has to be installed using an ROV, with weight being balanced by flotation.

- The CORK-Lite body must be self-centering, fit within the 16-inch casing, robust enough to withstand ROV operations, and extend $\sim 2 \mathrm{~m}$ above the ROV platform for ease of ROV manipulations.

- The seal must apply for either an over-pressured or under-pressured system.

- $\quad$ Any negative differential pressure across the top seal cap must be vented prior to eventual removal of downhole instruments.

- Two valves and ports (for redundancy) must attach to and penetrate the body for pressure monitoring within the borehole.

- Any instrument string has to fit within the steel pipe used as the CORK-Lite body.

- For safety, the instrument package must reside within the casing; intakes for fluid sampling must extend into the open borehole in an attempt to get "clean" borehole fluids free of possible artifacts from the steel casing and cement above.

The cap was designed to fit on the top of the body and seal it using a rubber gasket (Fig. 4). In case the borehole formation is over-pressured, four latching dogs are included. These dogs are activated by a mechanical lever system that forces the dogs in place through vertical motion of a floating nut driven by a power screw with attached handle. A two-way valve (closed in the horizontal position) is included in the cap. This valve is necessary to equalize the pressure before removing the cap if the borehole is under-pressured. A pad eye is welded under the cap to attach the downhole instrument string.

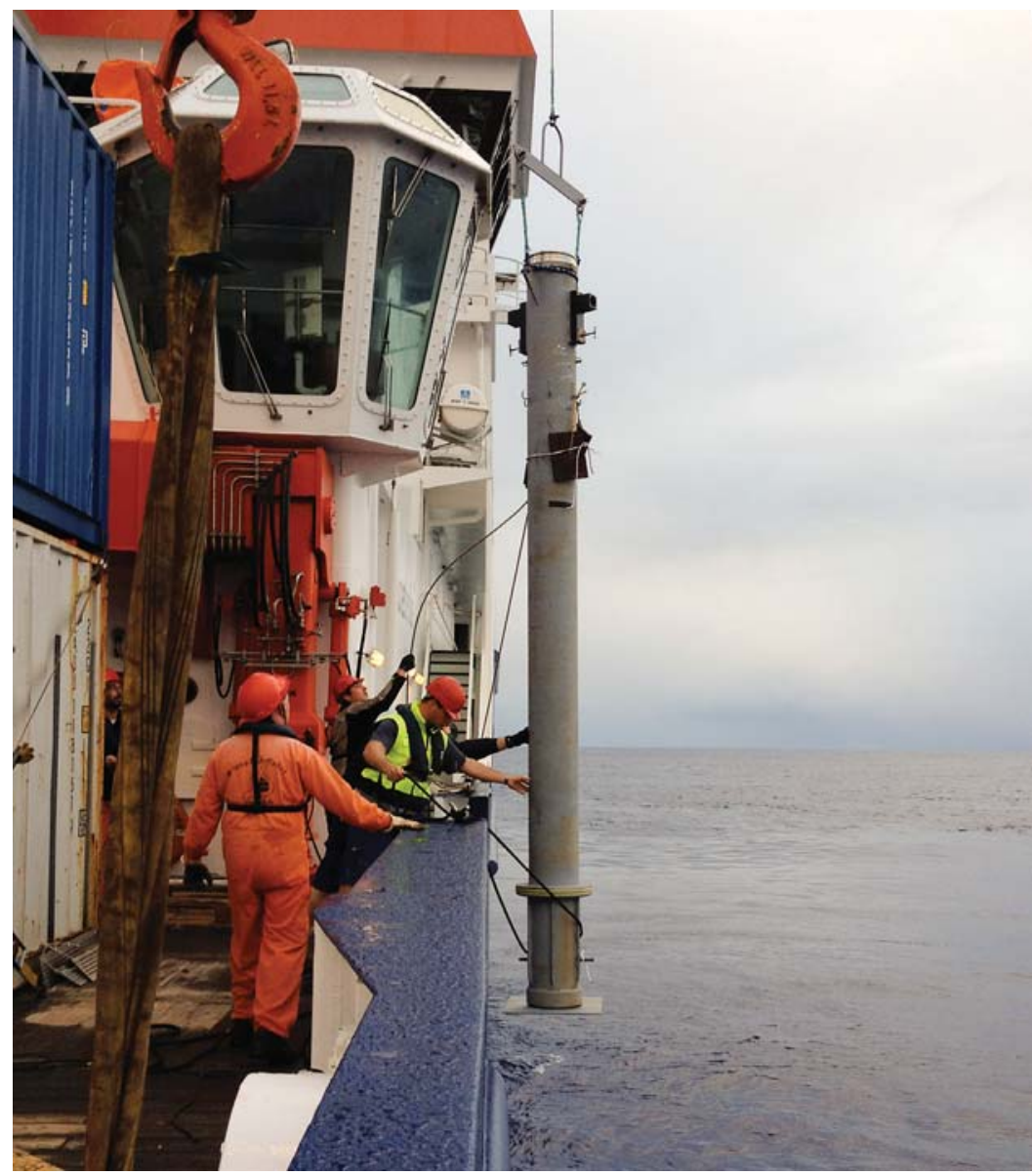

The CORK-Lite body is lowered over the side of the R/V Maria S. Merian The boot is held in place with a tee handle and secured with a bungie. The lifting bar assemblely is attached to the body with triple-strand polyproplyene rope and floats above. Extra Alvin dive weights were attached to the hooks for faster descent.
The downhole instrument string utilized components from Exp. 336 (osmotic pumps, coils of small bore sample tubing, support rods and various connectors) that were designed for deployment within the 3 -inch confines of the Exp. 336 CORKs. With the larger diameter available to the CORK-Lite, seven osmotic packages were coupled into one unit (Fig. 5). These packages include standard, dissolved gas, acid addition, enrichment, BOSS (fluid sampler that is preserved with RNAlater ${ }^{\circledR}$ for microbial-based analysis), and microbial colonization experiments (Jannasch et al., 2004; Wheat et al., 2011; Orcutt et al., 2010). A frame was designed to hold these packages, protect them during

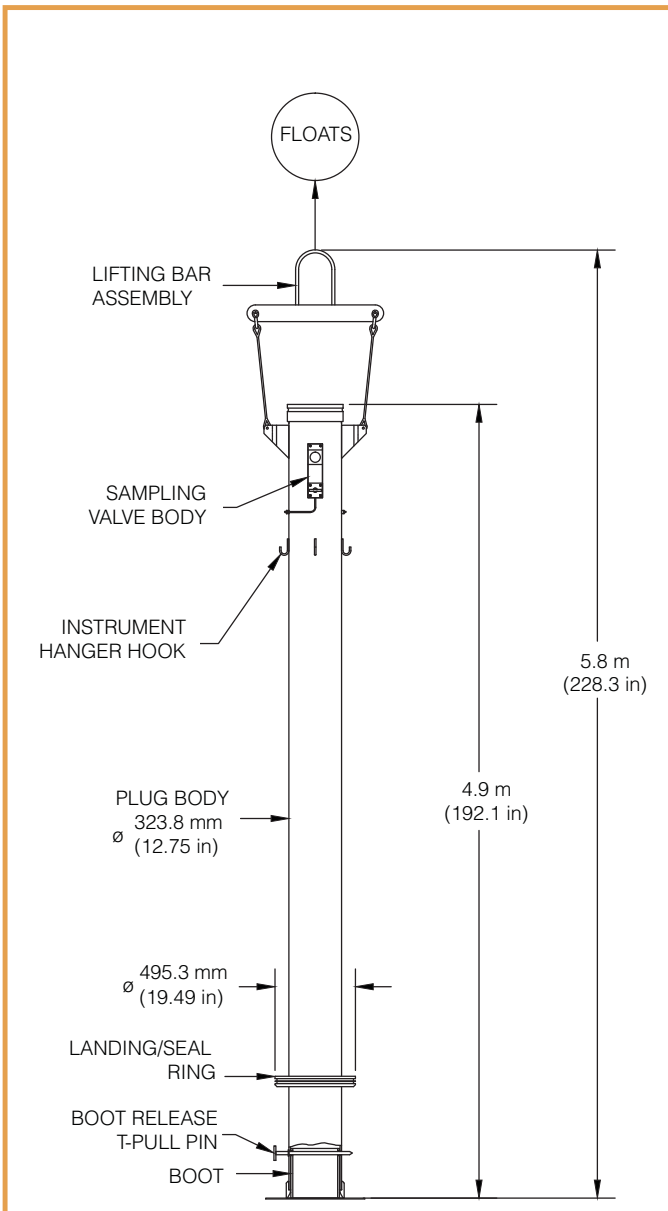

Figure 3. Schematic of the CORK-Lite body during free fall to the seafloor. 
deployment and recovery, and guide them into the CORK-Lite body. These frame components have a diameter of 10.75 inches, which easily fit through the 12-inch CORK-Lite body (12-inch I.D.). Because of borehole instability issues within other CORKs, we placed the instrument package near the bottom of the casing yet have the sample intakes extend meters into the open portion of the borehole. Intakes were protected with Tygon tubing and attached to a strength member (rope) and sinker bar. A weak link was positioned just below the instrument package in case the borehole is unstable and traps the sinker bar. Thus, the instrument package can be recovered even if the sinker bar becomes entombed.

The pressure monitoring device was developed at the Pacific Geoscience Centre (Sidney, BC, Canada), identical to most systems deployed on CORKs today, including those deployed on IODP Exp. 336 and previously on Exp. 327 and 328 (see technical descriptions in Davis et al., 2010; Fisher et al., 2011; Edwards et al., 2012b). The instrument includes batteries, electronics, two absolute pressure gauges (Paroscientific Model 8B-7000; one to monitor the formation and the other to monitor the seafloor), a data logger (set to sample pressure and temperature every two minutes like the Exp. 336 CORKs in IODP Holes U1382A and U1383C), an underwater mateable connector (Teledyne ODI), and a stainless steel line that connects to an ROV-deployable hydraulic coupler that fits in the valve package on the CORK-Lite body.

\section{ROV Operations}

Operations were conducted with the U.S.-operated ROV Jason from the German research vessel R/V Maria S. Merian during expedition MSM 20/5. The ROV platform was inspected on Jason dive J2-623 (20 April 2012). Before the next dive the CORK-Lite body was deployed with $\sim 770 \mathrm{lbs}$ of flotation. During the second dive the CORK-Lite was located, transported to the borehole, and lowered into place. A black stripe was painted on the body prior to deployment and used as an indicator that the body was in the proper position. After the subsequent dive the downhole instrument string was deployed. The instrument string included (from bottom to top) descent weights, a sinker bar, a 12-m-long three-strand polyproplyene rope with a weak link and intakes that extended $8 \mathrm{~m}$ from the instrument package, the instrument package (seven OsmoSampler packages, and three self-contained temperature recorders), a 50-m length of 3/8-inch spectra, the top plug, and flotation. The instrument string was located and installed, and the valves were closed. Later in the dive program the pressure logger was attached,

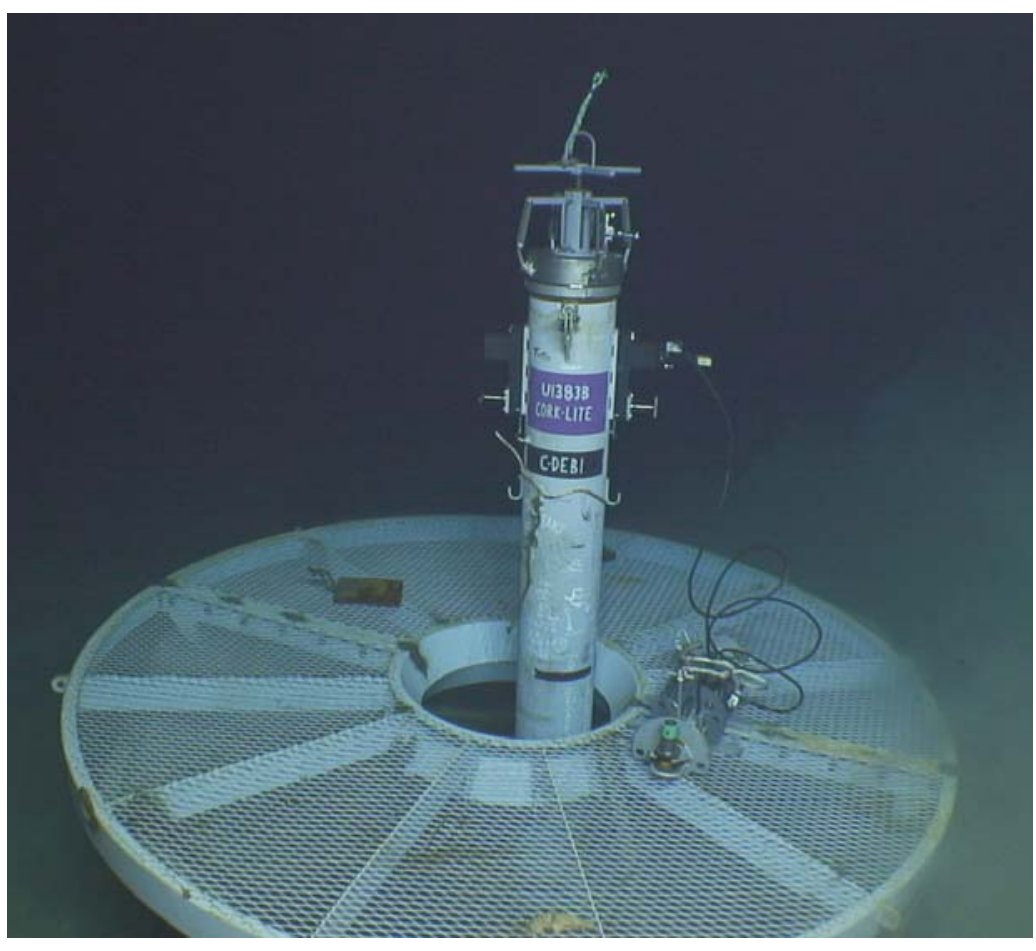

A CORK-Lite was successfully deployed and instrumented in IODP Hole U1383B. The cap (silver material above the gray pipe) is secured to the body utilizing the handle with a short piece of rope that originally was connected to flotation. The pressure logger rests on the ROV platform and is connected to the CORK-Lite body.

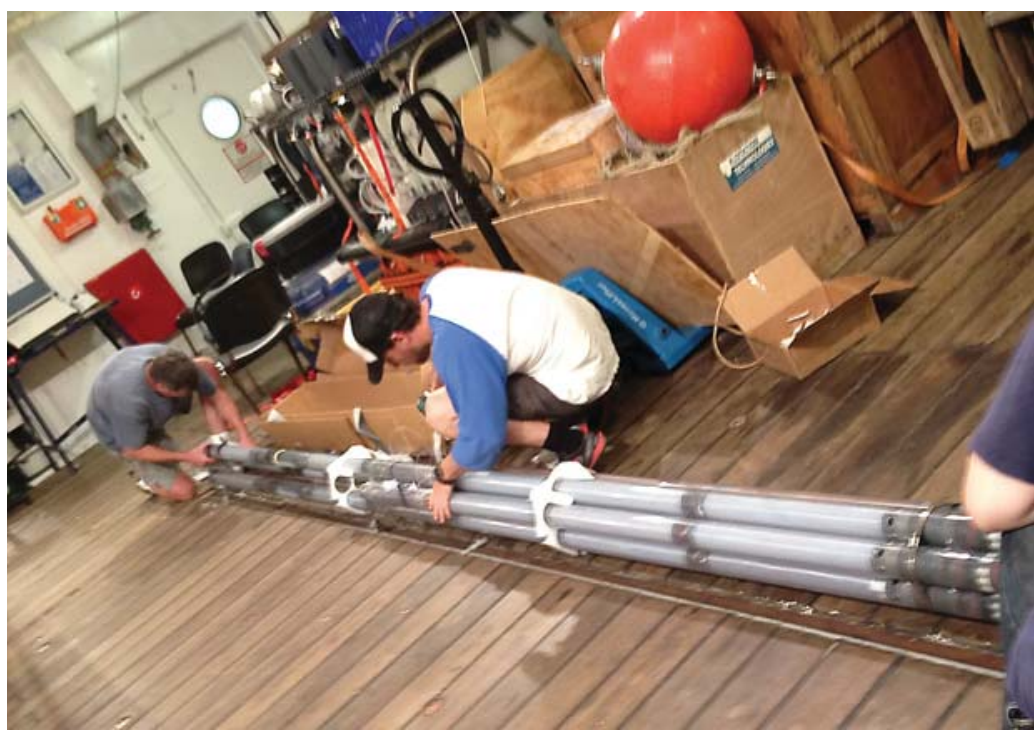

The downhole instrument package is fabricated before connecting it to the intake and ropes that space the package at the proper depth in the borehole. Seven smotic packages are arranged in a bundle.

and the data set that was retrieved indicated that the CORK-Lite was sealed (Fig. 6).

\section{Future Applications}

The design, fabrication, and operational effort at Hole U1383B illustrate the engineering potential to seal and instrument any of the tens of legacy boreholes that have been drilled into basement and cased through the sediment, leaving tens to hundreds of meters (in some cases up to 1500 meters) of open borehole (Edwards et al., 2012a). 
Placing sensors, samplers, and experiments in legacy boreholes could address a range of fundamental questions about conditions and processes within igneous oceanic crust. For example, the basaltic crustal aquifer plays a substantial role in cooling the Earth, regulating biogeochemical cycles within the oceans, and providing differences in redox potentials (i.e., between oxidizing seawater and reducing basaltic minerals) that

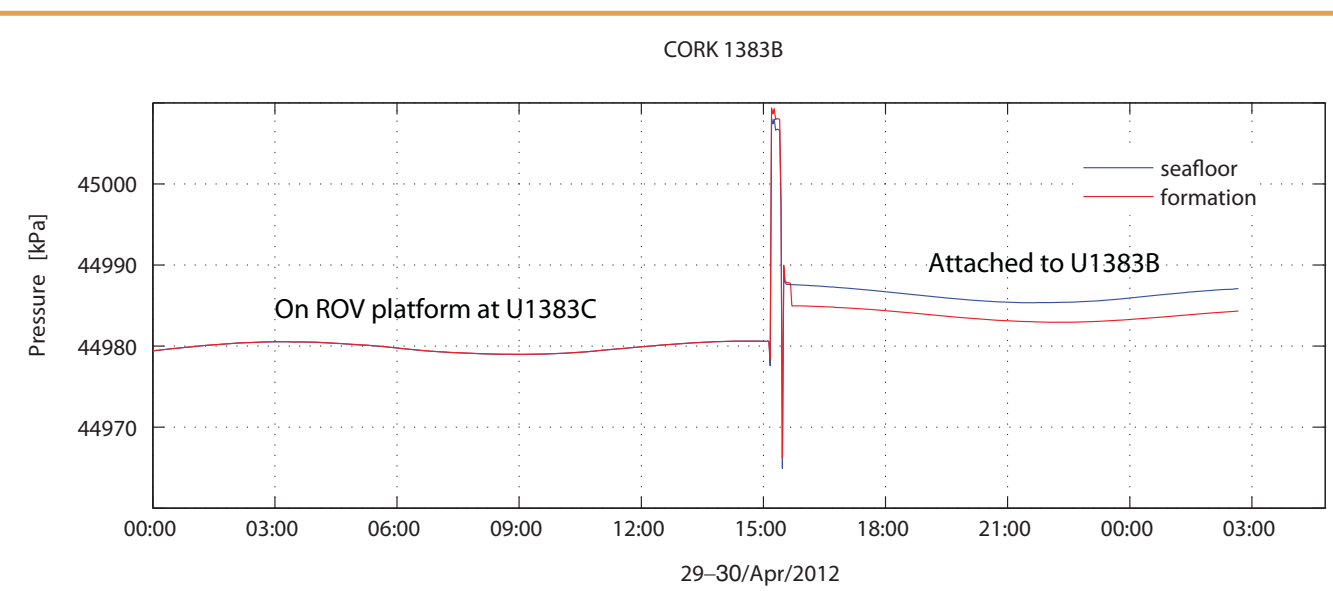

Figure 6. Pressure data from the CORK-Lite at IODP Hole 1383B. Before the instrument was attached, both sensors monitored bottom seawater on the ROV platform at Hole U1383C. After attachment, the two readings are different, signifying that the borehole is sealed and under-pressured relative to bottom seawater. offer great potential for

abiotic and biologically-mediated electron transfer reactions (Bach and Edwards, 2003; Fisher and Wheat, 2010). With appropriate instrumentation in selected legacy boreholes, we will be able to provide a better measure of the range of biogeochemical processes within the basaltic crust and the global significance of these processes. Legacy boreholes can serve other communities as well, for example, by providing access for a range of sensor suites for geological and geophysical studies.

Because legacy boreholes are typically cased with 10.75-inch pipe or larger, they can accept a range of sensors and instruments that typical CORKs cannot accept (many limit internal instrument diameters to 3.5 inches). Furthermore, there are a number of instrument suites developed by Schlumberger Limited that cannot be used in typical IODP boreholes but could be used in legacy boreholes. Although the initial CORK-Lite did not include electrical cables or an umbilical, future CORK-Lites could be modified to include such connections that penetrate the cap for seafloor interrogation of downhole sensors. Also, it is conceivable to deploy swellable packers, baffles, and other means to eliminate or minimize vertical fluid exchange within the borehole, allowing one to examine specific geologic or hydrologic horizons.

For some applications CORK-Lite provides an inexpensive alternative. It is especially useful for boreholes with single horizons, as it allows for the use of less armored and less expensive umbilicals, and it eliminates the need for an inner casing string or extensive wellhead structure. Furthermore, deploying such systems into legacy boreholes is independent from the drilling schedule. In some ways the CORK-Lite is a rejuvenation of the original CORK concept (Davis et al., 1992), but it is much more versatile. IODP Hole U1383B is just the start! We envision future CORK-Lites that address a range of scientific questions, utilizing a variety of instruments, sensors, and experiments.

\section{Acknowledgements}

We want to thank the engineering and operational staff involved in IODP Exp. 336, the crew of the R/V Maria S. Merian, and the team that operates the ROV Jason. Funding was awarded from the Gordon and Betty Moore Foundation, the German Science Foundation (DFG), and the National Science Foundation (NSF) through the STC Center for Dark Energy Biosphere Investigations (C-DEBI) (0939564) and individual research grants to CGW (OCE-0939564 and 1030061), KJE (OCE-1060634) and KB (OCE-0946795 and 1060855 for pressure-logging system). This is C-DEBI contribution number 132 .

\section{References}

Bach, W., and Edwards, K.J., 2003. Iron and sulfide oxidation within the basaltic ocean crust: Implications for chemolithoautotrophic microbial biomass production. Geochim. Cosmochim. Acta, 67(20):3871-3887, doi:10.1016/S0016-7037(03) 00304-1

Davis, E.E., Becker, K., Pettigrew, T., Carson, B., and MacDonald, R., 1992. CORK: A hydrologic seal and downhole observatory for deep-ocean boreholes. In Davis, E.E., Mottl, M.J., Fisher, A.T., et al., Proc. ODP, Init. Repts., 139: College Station, TX (Ocean Drilling Program), 43-53. doi:10.2973/ odp.proc.ir.139.103.1992

Davis, E.E., Malone, M.J., and the Expedition 328 Scientists and Engineers, 2010. Cascadia subduction zone ACORK observatory. IODP Prelim. Rept., 328. doi:10.2204/iodp. pr.328.2010

Edwards, K.J., Becker, K., and Colwell, R., 2012a. The deep, dark energy biosphere: Intraterrestrial life on Earth. Annu. Rev. Earth Planet. Sci., 40:551-568. doi:10.1146/annurev-earth $-042711-105500$

Edwards, K.J., Wheat, C.G., Orcutt, B.N., Hulme, S., Becker, K., Jannasch, H., Haddad, A., et al., 2012b. Design and deployment of borehole observatories and experiments during IODP Exp. 336. Mid-Atlantic Ridge flank at North Pond. 
In Edwards, K.J., Bach, W., Klaus, A., and the Expedition 336 Scientists, Proc. IODP, 336. Washington, DC (Integrated Ocean Drilling Program Management International, Inc.), in press.

Expedition 336 Scientists, 2012. Integrated Ocean Drilling Program Expedition 336 Preliminary Report. Mid-Atlantic Ridge microbiology, Initiation of long-term coupled microbiological, geochemical, and hydrological experimentation within the seafloor at North Pond, western flank of the Mid-Atlantic Ridge, IODP Prelim. Rept., 336. doi:10.2204/iodp.pr.336. 2012

Fisher, A.T., and Wheat, C.G., 2010. Seamounts as conduits for massive fluid, heat, and solute fluxes on ridge flanks. Oceanography, 23(1):74-87. doi:10.5670/oceanog.2010.63

Fisher, A.T., Wheat, C.G., Becker, K., Cowen, J., Orcutt, B., Hulme, S., Inderbitzen, K., et al., 2011. Design, deployment, and status of borehole observatory systems used for single-hole and cross-hole experiments, IODP Expedition 327, eastern flank of Juan de Fuca Ridge. In Fisher, A.T., Tsuji, T., Petronotis, K., and the Expedition 327 Scientists, Proc. IODP, 327: Washington, DC (Integrated Ocean Drilling Program Management International, Inc.). doi:10.2204/ iodp.proc.327.107.2011

Jannasch, H.W., Wheat, C.G., Plant, J., Kastner, M., and Stakes, D., 2004. Continuous chemical monitoring with osmotically pumped water samplers: OsmoSampler design and applications. Limnol. Oceanogr. Methods, 2:102-113. doi:10.4319/ lom.2004.2.102

Orcutt, B., Wheat, C.G., and Edwards, K.J., 2010. Subseafloor ocean crust microbial observatories: Development of FLOCS (FLow-through Osmo Colonization System) and evaluation of borehole construction methods. Geomicrobiol J., 27(2):143-157. doi:10.1080/01490450903456772

Schmidt-Schierhorn, F., Kaul, N., Stephan, S., and Villinger, H., 2012. Geophysical site survey results from North Pond (MidAtlantic Ridge). Proc. IODP, 336: Washington, DC (Integrated Ocean Drilling Program Management International, Inc.), in press.

Wheat, C.G., Jannasch, H.W., Kastner, M., Hulme, S., Cowen, J., Edwards, K., Orcutt, B.N., and Glazer, B., 2011. Fluid sampling from oceanic borehole observatories: Design and methods for CORK activities (1990-2010). In Fisher, A.T., Tsuji, T., Petronotis, K., and the Expedition 327 Scientists, Proc. IODP, 327: Washington, DC (Integrated Ocean Drilling Program Management International, Inc.). doi:10.2204/ iodp.proc.327.109.2011

\section{Authors}

C. Geoffrey Wheat, Global Undersea Research Unit, University of Alaska Fairbanks, P.O. Box 475, Moss Landing, CA 95039, U.S.A., e-mail: wheat@mbari.org

Katrina J. Edwards, Department of Biological Sciences, Marine Environmental Biology Section, University of Southern California, Los Angeles, CA 90089, U.S.A., e-mail: kje@usc.edu
Tom Pettigrew, Pettigrew Engineering, 479 Nine Mile Road, Milam, TX 75959, U.S.A., e-mail: pettigrew.engineering@windstream.net

Hans W. Jannasch, Monterey Bay Aquarium Research Institute, 7700 Sandholdt Road, Moss Landing, CA 95039, U.S.A., e-mail: jaha@mbari.org

Keir Becker, University of Miami, 4600 Rickenbacker Causeway, Miami, FL 33149, U.S.A., e-mail: kbecker@ rsmas.miami.edu

Earl E. Davis, Pacific Geoscience Centre, Geological Survey of Canada, 9860 West Saanich Road, Sidney, BC V8L 4B2, Canada, e-mail: edavis@nrcan.gc.ca.

Heiner Villinger and Wolfgang Bach, Department of Geosciences, University of Bremen, Klagenfurter Strasse, 28359 Bremen, Germany, e-mail: vill@uni-bremen.de, wbach@uni-bremen.de 